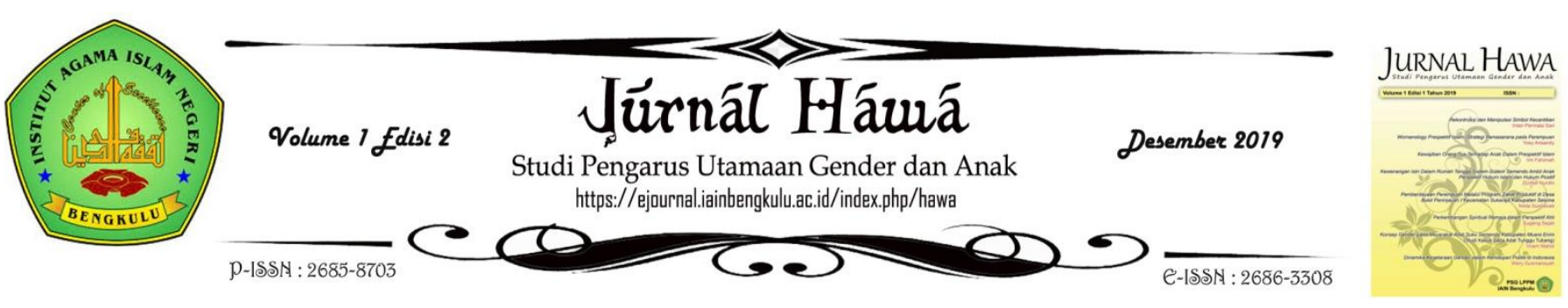

\title{
"Homoseks Ketemu Tuhan": Resistensi Kaum Gay dan Pertahanan Relasi Homoseksualitas dalam Fiksi Populer Indonesia
}

\author{
Andriadi, M.A. \\ Andriadi@iainbengkulu.ac.id \\ Tadris Bahasa Inggris IAIN Bengkulu
}

\section{Info Artikel}

Diterima: Oktober 2019

Disetujui: Oktober 2019

\section{Dipublikasikan:}

Desember 2019

\begin{tabular}{l} 
Reyword \\
\hline Resistance, Gay, \\
Homosexuality \\
Relations
\end{tabular}

\section{Kata Kunei}

Resistensi,

Gay, Relasi Homoseksualit as

\section{Abstract}

"Homosexs Meet God": Gay Resistance and Defense of Homosexuality Relations in Indonesian Popular Fiction. The subject of this research is to examine the representation of gay couple relations in the Homosexual Meet the Lord's novel by Rini Kristina to describe interactions between fellow people in society which is full of norms, customs, culture and religion control; and the resistance they carry out in maintaining their sexual identities as same-sex lovers so that their presence can be accepted in societies that tend to marginalize them. This research uses a qualitative method with a textual analysis approach. As a result, homosexuals know an agreement to establish a relationship like a relationship that is lived by heterosexual couples, love each other, and fill each other. Homosexual relations that lived by the characters, namely: monogamy, polyamori, and Friends But Intimate (TTM). To maintain homosexual relations that are contrary to the norms prevailing in society, gays carry out resistance by living a life filled with falsehood (in the closet), and running a life with a bicultural identity. Relationships that are run by gays will never last and are more likely to fulfill the same sex needs, and they put up a fight by wearing a mask that presents themselves as heterosexual men in order to avoid social pressure.

\section{Abstrak}

"HOMOSEKS KETEMU TUHAN": Resistensi Kaum Gay dan Pertahanan Relasi Homoseksualitas dalam Fiksi Populer Indonesia Pokok pembahasan dalam penelitian ini adalah menelaah representasi relasi pasangan gay dalam novel Homoseks Ketemu Tuhan Karya Rini Kristina untuk menggambarkan interaksi-interaksi antar sesama kaum ini di tengah masyarakat yang penuh dengan kontrol norma, adat, budaya, dan agama; dan resistansi yang mereka lakukan dalam mempertahankan identitas seksualnya sebagai pecinta sesama jenis sehingga kehadirannya dapat diterima dalam masyarakat yang cenderung memarginalkan mereka. Penelitian ini menggunakan metode kualitatif dengan pendekatan tekstual analisis. Hasilnya, kaum homoseksual mengenal sebuah kesepakatan untuk menjalin sebuah relasi layaknya relasi yang dijalani oleh pasangan heteroseksual, saling mencintai, dan mengisi satu sama lain. Relasi homoseksual yang dijalani tokoh, yaitu: monogami, poliamori, dan Teman Tapi Mesra (TTM). Untuk mempertahankan relasi homoseksual yang bertentangan dengan norma yang berlaku dalam masyarakat, kaum gay melakukan resistensi dengan cara menjalankan kehidupan yang penuh dengan kepalsuan (in the closet), dan menjalankan kehidupan dengan identitas bicultural. Relasi yang dijalankan kaum gay tidak akan pernah abadi dan lebih cenderung pemenuhan kebutuhan seks sejenis semata, dan mereka melakukan perlawanan dengan mengenakan topeng yang menampilkan dirinya sebagai pria heteroseksual demi menghindari tekanan sosial masyarakat. 


\section{Pendahuluan}

"Badrun mengakui bahwa menjadi hombreng sudah takdirnya. $Y a$, ia memang diciptakan untuk menjadi hombreng"

(Kristina, 2011: 133)

\section{Homoseksual adalah}

ketertarikan seksual terhadap jenis kelamin yang sama (Feldmen, 1999: 17). Homoseksual mengacu pada interaksi antara pribadi yang berjenis kelamin sama baik secara situasional ataupun berkelanjutan. Pada saat ini kata homoseks digunakan sebagai istilah untuk hubungan seksual di antara orang-orang yang berjenis kelamin sama, khususnya merujuk kepada pria homoseks. Perlu diketahui bahwa seorang gay merupakan sosok laki-laki tulen, begitu macho, bersih, dan sangat terawat dan sulit dibedakan dengan lelaki heteroseksual karena secara fisik penampilannya hampir sama dengan lelaki normal pada umumnya, tidak seperti kalangan waria yang kewanita-wanitaan, seorang gay tetap menunjukkan garis tegas seorang laki-laki, gagah, dan begitu mempesona terutama bagi kaum hawa.

Bukan perkara mudah mengembalikan jati diri seseorang menjadi heteroseksual karena selain masalah pilihan hidup, para kaum homoseksual merasa mencintai pasangan sejenis suatu panggilan jiwa. Usaha menjadi heteroseksual adalah pengkhianatan perasaan karena pada dasarnya jiwa mereka lebih memilih pasangan sejenis untuk dicintai. Menurut Dianawati (2013: homoseksual sebenarnya merupakan pilihan identitas seseorang. Oleh karena itu, cara apapun yang digunakan untuk tindakkan penyembuhan tidak selamanya akan berhasil.

Menjalankan hubungan sejenis secara terang-terangan (coming out of the closet) di Indonesia bukan perkara gampang karena masyarakat hanya membenarkan orientasi heteroseksual. Penolakan kaum homofobia yang terkesan irasional cukup membahayakan jiwa pelaku. Agama pun digunakan sebagai tombak untuk menyerang dan menghakimi mereka. Kondisi semacam ini menyebabkan kaum gay mengalami kecemasan sosial (Rakhmahappin \& Prabowo, 2014: 201). Sedangkan kebutuhan seks seorang gay adalah hubungan sesama jenis. Tentu 
saja perbuatan tercela ini tidak dapat diterima oleh masyarakat. Namun seks adalah kebutuhan jasmani setiap individu dewasa. Dalam pemenuhan kebutuhan ini mustahil digantikan dengan sesuatu yang tidak sesuai dengan pilihan mereka.

Fenomena percintaan antara pasangan gay sudah akrab di telinga masyarakat kita. Walaupun masih sangat tabu dalam budaya, tetapi selalu saja menarik untuk dibicarakan. Dari berbagai cerita kaum gay yang ada, peneliti fokus pada Novel Homoseks Ketemu Tuhan karya Rini Kristina karena novel ini dianggap memberikan wacana kompleks yang menarasikan kisah kehidupan kaum gay, terutama sisi resitensi demi mempertahankan relasi homoseksualitas dalam menghadapi tekanan sosial pada masyarakat pedukuhan yang homofobia. Berlatar pada Dukuh Cengkehan, Kota Santri Jombang, yang lebih dikenal sebagai "Dukuh Larangan", dijuluki Dukuh Larangan karena gemparnya peristiwa homoseksual di daerah tersebut. Cerita novel ini menggambarkan kehidupan beberapa tokoh utama yang bisa dikatan sebagai gay sejati/tulen, yaitu: Badrun, Jalil, dan Pak Lontar. Novel "Homoseks Ketemu Tuhan" yang berlatar di tengah masyarakat yang penuh dengan kontrol norma, adat, dan agama, menepatkan kaum gay sebagai kaum yang dimarjinalkan. Pengakuan identitas secara terang-terangan kepada masyarakat tentu saja akan menjadi persoalan yang tak akan pernah diterima bahkan menjadi suatu hal yang memalukan bukan hanya bagi gay tersebut tetapi juga bagi keluarganya. Namun, tuntutan kebutuhan seks sejenis harus dipenuhi karena seorang gay tak akan pernah mampu berpaling dari hasrat seks dan rasa cinta pada laki-laki.

Tulisan ini secara khusus akan berfokus pada bagaimana representasi relasi pasangan gay dalam novel Homoseks Ketemu Tuhan karya Rini Kristina; dan resistensi seperti apa yang dilakukan kaum gay dalam mempertahankan eksistensinya sebagai homoseksual. Tujuan penelitian ini yaitu untuk mengetahui representasi relasi pasangan gay dalam novel Homoseks Ketemu Tuhan Karya Rini Kristina sehingga dapat memberikan gambaran yang jelas mengenai interaksi-interaksi antara sesama kaum ini di tengah 
masyarakat yang penuh dengan kontrol norma, adat, budaya, dan agama yang cenderung memarginalkan mereka; dan untuk mengetahui resistansi yang dilakukan kaum gay dalam mempertahankan identitas seksualnya sebagai pecinta sesama jenis sehingga kehadirannya dapat diterima di tengah-tengah kuasa heteronormativitas dalam masyarakat seperti layaknya kaum heteroseksual.

Isu gender sudah menjadi persoalan penting dibahas dalam kehidupan modern walaupun masalah ini masih sensitif dibicarakan di negara-negara yang hanya menganut nilai-nilai heteronormativitas. Isu gender akan terus berkembang menjadi wacana yang menarik disuguhkan sebagai topik utama artikel pada media massa dan objek formal pada penelitianpenelitian mutakhir.Penelitian mengenai resistensi dan relasi kaum gay sering dilakukan, seperti Rahayu, Satriana, dan Mahaswara (2015) melakukan penelitian yang berjudul Aplikasi Gay: Perjuangan dan Ruang Negosiasi Identitas bagi Kaum Gay Muda di Yogyakarta. Hasil penelitian menunjukkan bahwa keberadaan aplikasi membuat kaum gay lebih diakui, dapat berinteraksi luas, memfasilitasi keingintahuan serta kebutuhan mereka. Aplikasi menjadi salah satu media penegasan identitas dan negosiasi ruang. Keberadaan aplikasi, dapat dikatakan tidak lagi mendudukkan mereka dalam ruang yang eksklusif dan berjarak. Namun, membuka akses informasi dan keterbukaan terhadap siapapun yang ingin mengakses.

Zainuri (2018) melakukan penelitian berjudul Analisis Perilaku Homoseksual pada Mahasiswa STKIP Kota Bima. Hasil penelitian menunjukkan bahwa faktor penyebab terjadinya perilaku homoseksual di kalangan mahasiswa STKIP Bima yaitu adanya pengaruh teman sebaya dalam pergaulan dan akibat rasa trauma dalam hubungan percintaan. Dampak perilaku homoseksual dapat dilihat dalam dua hal yaitu dampak solidaritas sosial dan dampak biologis (terjangkit penyakit). Upaya pencegahan yang dilakukan adalah pendalaman pemahaman agama bagi para pelaku sebagai bekal untuk membentengi diri dari pengaruh negatif pergaulan dan pemberian pemahaman bagi para remaja dan pelaku homoseksual 
tentang dampak perilaku homoseksual dan bahayanya bagi kesehatan remaja.

Penelitian ini memiliki perbedaan yang sangat signifikan dengan dua penelitian terdahulu di atas. Rahayu, Satriana, dan Mahaswara (2015) fokus pada jaringan aktif media sosial khusus gay, seperti aplikasi Jack'd, Grindr, Hornet yang dapat memungkinkan kaum homoseksual remaja untuk berinteraksi dalam ruang yang lebih egaliter dan bebas intervensi. Zainuri (2018) fokus pada pemahaman faktor penyebab terjadinya perilaku Homoseksual di kalangan mahasiswa, memahami gejala yang ditimbulkan oleh pelaku Homoseksual, memahami serta mengupayakan pencegahan bagi pelaku homoseksual di kalangan mahasiswa STKIP Kota Bima. Sedangkan penelitian ini fokus pada representasi relasi pasangan gay pada karya sastra berupa novel dengan judul Homoseks Ketemu Tuhan Karya Rini Kristina untuk mengetahui interaksiinteraksi antara sesama dalam masyarakat yang penuh dengan kontrol norma, adat, budaya, dan agama yang cenderung memarginalkan mereka dan resistansi yang dilakukan mereka dalam mempertahankan identitas seksualnya sebagai pecinta sesama jenis di lingkungan heteroseksual. Oleh sebab itu, penelitian ini layak untuk dilakukan, agar memberikan manfaat secara teoritis dan praktis bagi masyarakat secara luas.

\section{Landasan Teori}

Teori queer merupakan suatu konsep yang secara garis besar membahas orientasi seksual yang menyimpang, yaitu homoseksual. Teori ini menawarkan pandangan bahwa orientasi seksual tidak hanya dilihat dari salah satu aspek saja seperti gender feminim/maskulin atau jenis kelamin (sex) pria/wanita. Orientasi seksual merangkul kedua aspek tersebut dalam mengidentifikasi seseorang. Teori ini fokus pada kerelaan identitas yang tidak hanya dipandang dari sisi fisik saja, tetapi juga sisi psikis. Rubin (1994: 17) mengatakan bahwa:

Gender affects the operation of the sexual system, and the sexual system hashad genderspecific manifestations. But although sex and gender are related, theyare not the same 
thing, and they form the basis of two arenas of social practice.

Pendapat ini memperjelas bahwa gender dan Jenis kelamin (sex) mempunyai andil dalam membentuk suatu orientasi seksual secara utuh. Gender dan Jenis kelamin (sex) memang saling berhubungan, tetapi kedua aspek tersebut tidaklah sama. Gender memang terbentuk sejak lahir, tetapi pengaruh dari luar, kondisi psikis, dan pengalaman masa lalu juga memberikan pengaruh besar pada perkembangan gender.

Menanggapi wacana yang ditawarkan novel Homoseks Ketemu Tuhan, Sedgwick (1990) dalam bukunya Epistemology of the Closet mengemukakan konsep coming out of the closet dirasa tepat untuk membedah persoalan tersebut. Secara harfiah, coming out of the closet berarti keluar dari lemari baju. Konsep tersebut merupakan metafora yang berarti terbuka mengungkapkan orientasi seksual sesama jenis (gay atau lesbian) seseorang bukanlah suatu tindakkan tunggal dan absolut. Orientasi seksual menyimpang ini dapat diumumkan secara terbuka pada orang-orang terdekat seperti keluarga dan teman, tapi tidak diungkap secara menyeluruh di hadapan kolega. Maka berada "di dalam" atau "di luar" lemari baju bukanlah dikotomi sederhana atau peristiwa sekali seumur hidup. Merahasiakan atau terbuka berada pada tingkat yang sama dalam kehidupan.

Selain itu istilah "in the closet" merupakan istilah yang umum di kalangan homoseksual sebagai bahasa lain dari homoseksual tertutup. Kata "closet" digunakan sebagai metafor untuk menyatakan ruang privat atau ruang sub-kultur, di mana seseorang dapat mendiaminya secara jujur, lengkap dengan keseluruhan identitasnya yang utuh. Dengan kata lain in the closet berarti orang yang menjalani kehidupannya dengan penuh kepalsuan, tidak bahagia dan tertekan oleh posisi sosial yang diterima dari masyarakat. Di sisi lain closet juga bermakna sebagai strategi akomodasi dan pertahanan yang diproduksi untuk menghadapi norma masyarakat heteroseksual di sekitar.

Tujuan kritik gay ini untuk menjadikan orientasi seksual sebagai kategori fundamental melakukan analisis pemahaman (Barry, 2010: 64). Seperti halnya kritik feminis, studi ini memiliki 
tujuan sosial dan politik, khususnya "sebuah rencana oposisi" terhadap masyarakat, sebab substansi studi ini didapat dari penolakan terhadap homofobia dan heteroseksisme.

Homofobia adalah penolakkan sosial terhadap kaum gay yang dianggap menyimpang dari tatanan dinamis masyarakat. Sadar atau tidak, sebagian besar orang mengembangkan perasaan yang tidak rasional, cenderung tidak mendasar, dan negatif terhadap kaum marjinal ini. Sekelompok orang seperti inilah yang disebut sebagai kaum homofobia seperti yang dijelaskan oleh Herek (2011: 2) bahwa," Homophobia, a term often used to describe hostile reactions to lesbians and gay men, implies a unidimensional construct of attitudes as expressions of irrational fears".

Homofobia muncul sebagai reaksi ketakutan berlebihan akan sisi negatif kaum homoseksual hingga bertindak berlebihan menanggapi persoalan penyimpangan seksual sehingga menyebabkan kaum gay tidak hanya gagal dalam usaha "coming out" tetapi juga tidak mampu menemukan identitas dirinya sebagai gay. Dengan menjadi homoseksual tertutup, kaum gay seperti mengenakan topeng, menampilkan diri sebagai pria heteroseks untuk melindungi diri dari cemoohan dan ejekkan kebanyakan kaum heteroseksual (Oetomo, 2003: 19). Demi menghindari tekanan sosial dan hegemoni anti gay, banyak kaum gay menampilkan perilaku maskulin agar tampil seperti kaum heteroseksual pada umumnya. Kaum gay yang menggunakan dua identitas (comming out the closet dan in the closet) disebut bikultur (Sedgewick, 1990: 23). Bikultur ini kerap diterapkan oleh kaum homoseksual tertutup (identitas in the closet).

Keputusan seorang gay untuk menggunakan identitas "comming out the closet" atau "in the closet" atau bikultur dipengaruhi oleh tatanan sosial dan ranah keagamaan (Tejalaksana, 2009: 4). Ranah agama hampir selalu menjadi dasar dan ujung tombak penolakkan masyarakat terhadap eksistensi kaum homoseksual. Terlebih lagi Indonesia sering dipandang sebagai negara religi, di mana agama dianggap sebagai dasar yang membawa pengaruh sosial terbesar terhadap tatanan, etika, dan norma masyarakat. Alasan itulah agama sering 


\section{Pembahasan}

1. Relasi Pasangan Gay Representasi Hubungan di Tengah Masyarakat Heteroseksual

Kaum homoseksual juga mengenal sebuah kesepakatan untuk menjalin sebuah hubungan. Relasi yang terjalin sama halnya seperti yang dijalani oleh pasangan heteroseksual, saling mencintai dan mengisi satu sama lain. Relasi pasangan gay dalam novel ini berupa: relasi monogini, poliamori, monogami, dan Teman Tapi Mesra (TTM)

Relasi monogami dapat dilihat pada hubungan antara tokoh Badrun dan Raka atau Pak Lontar dan Ulrich. Hubungan yang mereka jalani adalah satu pribadi dengan satu pasangan saja atau dari awal hingga akhir hanya berhubungan atau berkomitmen dengan satu orang saja. Namun, di luar pasangan tetapnya itu dimungkinkan juga terjadinya perselingkuhan secara diamdiam.

Biasanya perselingkuhan yang dilakukan hanya sebatas hubungan pemunuhan kebutuhan seks semata, bukan untuk jalinan hubungan tetap dan serius.

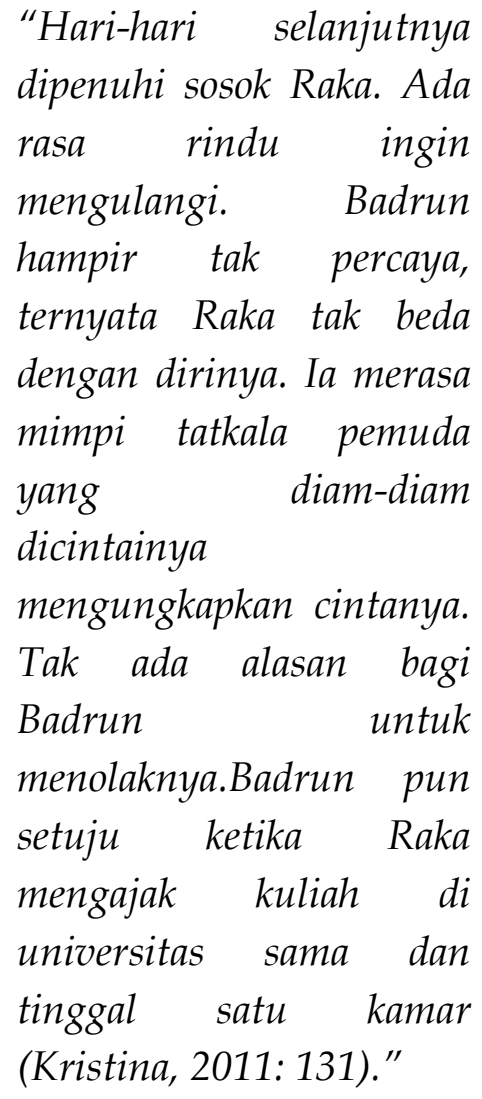

Penggambaran di atas menjelaskan bahwa Badrun dan Raka menjalin hubungan selama kuliah. Selama menempuh pendidikan, mereka tinggal satu kamar. Mereka menjalin kedekatan baik secara personal maupun seksual dalam kurun waktu yang cukup lama. Dalam novel ini Badrun dan Raka berpisah setelah mereka menyelesaikan studinya. Kebersamaan yang cukup lama menyebabkan terbangunnya kedekatan 
emosional yang sulit untuk saling melepaskan.

Dalam novel ini, relasi Pak Lontar dengan Ulrich dapat dikatakan sebagai relasi monogami sama seperti hubungan Badrun dan Raka.

“...Hubungannya dengan

Pak Lontar amat dekat. Sering sekali Pak Lontar mengantar Ulrich melakukan penelitian. Bahkan Pak Lontar pernah diajak keliling Eropa selama setahun. Keduanya juga mampir di Jerman ikut merayakan Chrisopher Street Day "Hari Kaum Gay"... Ulrich hanya dua tahun tinggal di Dukuh Cengkehan. Pak Lontar jatuh sakit sepeninggalnya.Tubuhnya kurus kering seperti orang patah hati (Kristina, 2011: 113 -114)."

Relasi tokoh Badrun, Pak Lontar, dan Jalil dalam novel ini disebut sebagai relasi poliamori, yaitu jalinan hubungan antara lebih dari dua orang yang saling mencintai dan saling berhubungan seksual. Pihakpihak yang terlibat biasanya bisa saling menerima satu sama lain sehingga praktis tidak ada rasa saling cemburu karena mereka bertiga juga saling berhubungan. Hubungan yang bersifat poliamori dapat dilihat dari cuplikan-cuplikan berikut ini:

\section{Badrun dan Pak Lontar}

"Benih kasih pada Pak Lontar tumbuh. Rindunya pada lakilaki itu menggelegak. Tak diindahkannya sakit dan dingin. Ia ingin bertemu Pak Lontar (Kristina, 2011: 133)."

\section{Badrun dan Jalil}

"Sudah, sudah Dik. Tangan sampean pasti capek." Jalil memegang pergelangan tangan Badrun pelan. Badrun pun berhenti mengoles. Ia terhentak ketika tangan Jalil satunya mengusap telapak tangannya. Spontan Badrun menatap Jalil. Kedua mata mereka beradu. Jantung Badrun tiba-tiba berdetak. Sorot mata Jalil mengingatkannya pada seseorang (Kristina, 2011: 32)."

\section{Pak Lontar dan Jalil \\ "Pak Lontar mendekat.Kedua tangannya memegang paha Jalil."Kau telah membantuku.Lahir batin dan sewaktu-waktu jika kuperlukan, jadi pantas kalau aku memberimu uang sebagai}


tanda terimakasih.Sedangkan mereka hanya kerja paroh waktu dan hanya memetik cengkeh (Kristina, 2011: 27)."

Ketiga kutipan di atas menunjukkan hubungan yang bersifat poliamori antara Badrun, Pak Lontar, dan Jalil. Mereka mengekspresikan cinta dengan menjalin hubungan yang melibatkan lebih dari dua orang dengan saling memiliki ketetarikkan secara emosional, fisik dan menjalin hubungan seksual sejenis. Ironisnya, mereka saling menerima satu sama lain tanpa didasari rasa cemburu. Pasangan poliamori ini awalnya dimulai dari hubungan seksual semata, namun akhirnya tumbuh perasaan di antara mereka. Hubungan ini pun dijalin mereka karena keinginan untuk memberontak nilai religius dan budaya heteroseksual yang mendarah daging dalam masyarakat Pedukuhan dan juga memberontak ekspektasi keluarga.

Hubungan Pak Lontar dengan beberapa pemuda desa bisa disimpulkan sebagai relasi
Teman Tapi Mesra (TTM), yaitu sebuah hubungan saling membutuhkan saja atau relasi antara dua orang atau lebih tanpa komitmen, dapat melibatkan hubungan seksual atau tidak. Biasanya hubungan seksual akan muncul apabila mereka sama-sama membutuhkan. Di luar itu mereka berteman biasa, tanpa melibatkan rasa cemburu apabila salah satu dari mereka berhubungan dengan orang lain. Hal ini dapat dilihat pada kutipan berikut:

"Pak Lontar yang
ketagihan bercinta dengan
sejenisnya lantas menculik
pemuda-pemuda tampan yang
dikehendakinyar untuk
dikenalkan pada permainan
terlarang itu. Usai itu, mereka
diberi segebok uang dan
diancam agar tidak
mengatakan hal itu pada orang
lain. Kemudian, Pak Lontar
tidak perlu bersusah payah
menculik pemuda lagi. Karena
mereka, puluhan pemuda
Cengkehan telah antri
mewarkan diri (Kristina, 201:
114)."

Kutipan diatas menjelaskan bahwa relasi Pak Lontar dengan pemuda desa tanpa komitmen. Relasi 
mereka hanya atas dasar saling membutuhkan dan menguntungkan saja. Pak Lontar memenuhi kebutuhan biologis, dan pemuda desa yang sebagian besar adalah pengangguran butuh uang.

2. Resistensi Tokoh dalam mempertahankan

eksistensinya sebagai
homoseksual

Indoesia, negara yang dikontrol oleh tatanan norma, adat, budaya serta agama, tentunya kehidupan gay dipandang sebagai sesuatu yang menyimpang dan bertentangan dengan norma yang berlaku dalam masyarakat. Oleh karena itu, terdapat berbagai resistensi yang dilakukan kaum pecinta sesama jenis ini sebagai strategi akomodasi dan pertahanan untuk menghadapi norma masyarakat heteroseksual di sekitarnya. Resistensi yang dilakukan tiga tokoh gay dalam novel ini dalam mempertahankan relasi homoseksual di tengah kuasa heteronormativitas dapat dijelaskan sebagai berikut:

a. Kehidupan yang Penuh Kepalsuan
Dalam novel ini, Badrun dinarasikan sebagai seorang laki-laki tampan dan maskulin. Gadis-gadis desa tergila-gila karena performa fisiknya yang menawan. Ia memutuskan untuk menggunakan identitas "in the closet" sebagai perlawanan terhadap kondisi sosial yang tidak membenarkan identitas homoseksualnya. Bahkan ia menjelma menjadi seorang guru ngaji bagi anak-anak di langgar desa, sehingga identitas seksualnya dapat disembunyikan dengan rapi.

"...Bahkan, ia sempat membenarkan bahwa menjadi hombreng sudah takdirnya. Jalan hidup yang memang harus dijalani. Ya, ia memang diciptakan untuk jadi hombreng (Kristina, 2011: 133)."

Bagi Badrun orientasi homoseksual telah menjadi takdir yang memang harus dijalaninya. Bukan perkara mudah mengembalikan identitas heteroseksual seseorang. Untuk menghindari tekanan sosial, 


Badrun menjalankan
kehidupan yang penuh
dengan kepalsuan
walaupun sebenarnya ia
tidak bahagia bahkan
tertekan dengan posisi
sosial yang diterimanya dari
masyarakat.

b. Identitas Bikultural - in the closet dan coming out the closet

Tokoh Pak Lontar dalam novel ini dinarasikan sebagai seorang juragan cengkeh yang gagah dan maskulin. Ia memutuskan menggunakan identitas bikultural (in the closet dan coming out the closet) demi mempertahankan

kelanggengan identitas homoseksualnya di tengah pengaruh sosial dan ranah agama yang berlaku dalam masyarakat pedukuhan. Ia berusaha tampil dengan prilaku maskulin bahkan menikahi seorang janda beranak satu demi menghindari tekanan sosial dari hegemoni anti gay. Hal ini dapat dilihat pada cuplikan berikut:

"...Ketika itu, kedua
orang tua saya gencar-
gencarnya menyuruh saya

menikah. Dengan wanita tentunya.Saya bingung karena saya tidak mencintai satupun wanita.Kemudian saya ungkapkan kegundahan ini pada Nani. Intinya, Nani tidak keberatan saya nikahi. Nani sudah paham siapa saya, sehingga ia bisa menerima saya apa adanya, dan saya tidak berdosa karenanya. Nani wanita yang sabar dan setia.Saya sangat menyayanginya, namun saya gagal mencintainya (Kristina, 2011: 103)."

Pernikahan bagi Pak Lontar hanyalah sebagai resistensi terhadap pengaruh sosial untuk menhindari cemoohan masyarakat. Pengakuan identitas pada keluarga yaitu istri tanpa mengumumkannya pada masyarakat luas berarti ia menggunakan identitas "Coming out the closet" sebagai wujud resistensi mempertahankan identitas seksualnya.

Pak Lontar juga purapura lumpuh untuk menghindari kewajibannya sebagai suami dan menutupi perbuatan seksual menyimpang yang 
masih terus berlanjut. Hal ini dapat dilihat pada kutipan berikut:

"Semula Hamidah
mengira pamannya lumpuh
sungguhan. Hingga kemudian
ia memergoki pamannya
mondar-mandir di ruang
kerjanya yang terkunci. Jika ia
ada keinginan berhubungan
seks cukup telpon "link" nya.
Pak Lontar tak mau lagi
berkencan dengan sembarang
laki-laki, apalagi yang masih
muda. Hamidah sudah tahu
hal itu sebab pernah menguntit
kepergian pamannya (Kristina,
2011: 128)."

Tokoh Pak Lontar menggunakan identitas bikultural sebagai wujud resistensi dengan mengenakan topeng menampilkan diri sebagai pria heteroseksual untuk menghindari tekanan sosial sehingga dapat terus berhubungan dengan pasangan sejenisnya tanpa dicurigai masyarakat sekitar.

Selain Pak Lontar, tokoh Jalil juga menggunakan identitas bikultural. Ia pernah menikah namun bercerai. Pernikahan dengan wanita mengukuhkan lebel "normal" pada dirinya. Kemudian ia menikah lagi dengan Lilis. Hal ini dapat dilihat pada cuplikan berikut:

"Saya telah menikah dengan Lilis. Akad nikah berlangsung semingou yang lalu, lusa tinggal pestanya (Kristina, 2011: 123)."

Selama

pernikahannya, ia tetap menjalankan hubungan seks sesama jenis. Ini suatu bukti bahwa seorang homoseksual tetap belum mampu sepenuhnya berpaling dari laki-laki.

\section{Kesimpulan}

Kaum homoseksual memiliki kesepakatan untuk menjalin sebuah relasi layaknya relasi yang dijalani oleh pasangan heteroseksual, yaitu: monogami, poliamori, dan Teman Tapi Mesra (TTM). Untuk mempertahankan relasi yang bertentangan dengan norma yang berlaku dalam masyarakat, mereka melakukan resistensi, yaitu: menjalankan kehidupan yang penuh dengan kepalsuan (in the closet), dan menjalankan kehidupan dengan identitas bicultural. Hal ini mereka lakukan 
untuk mempertahankan identitas seksualnya sebagai pecinta sesama jenis sehingga kehadiranya dapat diterima di tengah-tengah masyarakat yang

\section{Daftar Pustaka}

Ajen, D. (2006). Pendidikan Sex dan Heteronormativiti. Jakarta: $\mathrm{Pt}$ Kawan Pustaka.

Barry, P. (2010). Pengantar Komprehensif Teori Sastra dan Budaya: Beginning Theory. Yogyakarta: Jalasutra.

Dianawati. (2006). Intisari psikologi abnormal. Yogyakarta: Pustaka Pelajar.

Feldmen, R. S. (1999). Understanding psychology the Fifth Edition. New York: Mc Graw-Hill Publishing Company.

Harek, M.(2010), "Selected Publications on Sexual Prejudice and Homophobia,"

Kristina, R. (2011). Homoseks Ketemu Tuhan. Yogyakarta: Jaringan Santri Menulis dan Kreasi Wacana.

Oetomo, D.(2013). Memberi Suara pada yang Bisu. Yogyakarta: Pustaka Marwa.

Rakhmahappin, Y \& Prabowo, A. (2014). Kecemasan Sosial Kaum Homoseksual Gay dan Lesbian, JIPT (Jurnal cenderung memarginalkan mereka.

Ilmiah Psikologi Terapan), Vol. 2, No. 2, 2014, H. 201.

Rahayu, P., Satriana, R \& Mahaswara, H.A. (2015). Aplikasi Gay: Perjuangan dan Ruang Negosiasi Identitas bagi Kaum Gay Muda di Yogyakarta, Jurnal Studi Pemuda, Vol. 3, No.2, 2014, H. 99.

Sedgwich, E. K. (1990). Epistemology of the Closet. Los Angeles: University of California Press.

Stein, A. (1994). "I Can't Even Think Straight" "Queer" Theory and the Missing Sexual Revolution in Sociology. Sociological Theory, Volume 12, No. 2.

Tejalaksana, R. (2009). Kaum Homoseksual: Para Korban yang Terlupakan. Retrieved on June 18, 2019 from http://his-sheltercommunity.blogspot.com/2 009/12/kaumhomoseksual-para-korbanyang.html.

Zainuri, M.I. (2018). Analisis Perilaku Homoseksual pada Mahasiswa STKIP Kota Bima. 
Andriadi, M.A.

"Homoseks Ketemu Tuhan": Resistensi Kaum Gay dan Pertahanan Relasi Homoseksualitas Dalam Fiksi Populer Indonesia

PPS Universitas Negeri

Makassar. 